\title{
Seasonal variation in growth of Berkshire pigs in alternative production systems
}

\author{
Hyeon-Suk Park ${ }^{1}$ and Sang-Hyon $\mathrm{Oh}^{1, *}$
}

* Corresponding Author: Sang-Hyon Oh Tel: +1-336-285-4807, Fax: +1-336-334-7288,

E-mail: soh@ncat.edu

'Department of Animal Sciences, College of Agriculture and Environmental Sciences, North

Carolina Agricultural and Technical State University, Greensboro, NC 27410, USA

Submitted Aug 4, 2016; Revised Sept 27, 2016; Accepted Nov 3, 2016
Objective: The objective of the present study was to investigate the effects of farrowing month (FM), parity and sex on the growth performance of Berkshire swine raised in alternative production systems.

Methods: A total of 40 farrowing records from 27 sows and 1,258 body weight (BW) records from 274 piglets collected over a two-year period were used for the analysis. The BWs were recorded at birth, weaning (28 d), 56, 84, 112, and 140 days. Any BW not recorded on schedule was recalculated to conform the days of age among corresponding BW records, using growth curves drawn with polynomial functions whose power was determined by the number of existing observations for each individual.

Results: The mean parity ( \pm standard deviation) of the sows was $3.42 \pm 2.14$. The sows that farrowed in June had the lowest number of total born with an average of $6.25 \pm 2.22$ piglets per sow. However, the lowest average number of piglets weaned at day 28 was found in sows that farrowed in May, as well as the highest number recorded for the stillborn piglets with an average of 2.67 piglets per sow. Moreover, the smallest increase in weight from birth to weaning occurred in piglets that were farrowed in May, which also corresponds with the average daily gain (ADG) of $0.29 \mathrm{~kg}$ and the last recorded weight measurement on day 140 of $41.69 \pm 1.45 \mathrm{~kg}$. Contrastingly, the highest growth rate was found among pigs farrowed in June, with the largest increase in weight of $7.55 \mathrm{~kg}$ from birth to weaning, the highest ADG of $0.51 \mathrm{~kg}$ from birth to 140 day of age and the highest BW of $74.70 \pm 1.86 \mathrm{~kg}$ recorded on day 140 .

Conclusion: Pigs farrowed in June also had the least number of piglets that died between birth and weaning. The zone of thermal comfort found in sows reared in indoor confinement systems did not improve the reproductive performance of the sows reared in an outdoor, alternative production system, while the growth performance of the piglets was improved when the ambient temperature was consistently hot or consistently cold.

Keywords: Berkshire; Pig; Growth; Alternative Production System

\section{INTRODUCTION}

Outdoor pig production has been paid increased attention by the public in the past decades [1]. With the outbreaks of diseases such as the foot and mouth disease, the mad cow disease, and the avian and swine influenza, food safety issues and animal/human health concerns have been raised in the recent years regarding confined systems. Furthermore, consumers have shown a higher preference in meat quality for organic animal products [2]. Concerns for animal welfare, food safety and animal/human health, along with the higher preference for organic animal products, caused the increased attention in alternative production systems, including "pasture-based" and deep-bedded hoop barns, which have the potential to address these issues, as well as to provide new opportunities for small, limited-resource farmers.

In recent years, there has been a decline in concerns regarding low productivity of sows and 
pigs raised outdoors [3]. Compared to pigs raised in intensive confinement systems, outdoor raised pigs that are allowed more space by the nature of the production system have superior meat quality and taste $[4,5]$. Furthermore, pork from pigs raised outdoors can fetch more than double the price of pork produced in confinement systems according to outdoor pig producers in the United States. Outdoor production systems can be a way in which small farmers take advantage of the niche market and target a specific audience with a preference for high quality meat produced in an animal friendly environment.

Anecdotal evidence suggest that some breeds of pigs perform better in an outdoor system than others, but few scientific studies exist that investigate the breeds or lines of pigs that actually excel in outdoor production facilities. Then, an important question that needs to be addressed is the type of breed that is best fitting to the outdoor system [3]. A breed known to have good meat quality when raised in confined systems, such as the Berkshire breed, can create an added value to the pork from pigs raised outdoors, which can already fetch more than double the price of pork produced in confinement systems. In Japan, high pricing has been established for pork produced from purebred Berkshires [6]. Such price formation is appropriate for animal products of an outdoor production system, in which high value products are necessary to account for its small scale.

Very few studies have been conducted that involve performance tests of purebred Berkshire pigs raised outdoors, due to the difficulties in measuring body weight (BW) and feed intake outdoors. A similar study conducted by Swantek et al [7] reported the feed intake and growth rate of purebred Berkshire pigs housed in hoop buildings in Iowa. Growth performance measurements were reported in terms of initial weight, final weight, and average daily gain (ADG). Direct comparison with the present study was not possible, however, due to the differences in growth performance measurements. Initial weight reported was not the same as birth weight, and the days of age for the final weight had a range of 30 days. Nonetheless, it is necessary to understand the different factors that might affect the performance of pigs raised outdoors despite the difficulties. For example, difference in growth performance may exist between different sexes in an unrestrained environment. Also, the outdoor environment changes according to the change of season, and because piglets are sensitive to the environmental temperature, especially during the first few days after birth, knowing when to breed the sows for optimum productivity and piglet survivability is important.

Because making alternative swine production more marketable to an upscale audience is important [8], the objective of this study was to investigate the factors, such as the farrowing month (FM), parity and sex, affecting growth performance of Berkshire breed raised in alternative production systems. This research will help determine the sustainability of outdoor pork production systems utilizing a systems-based research approach.

\section{MATERIALS AND METHODS}

The experiments were conducted at the North Carolina Agricultural \& Technical State University (NC A\&T SU) farm, which is located in Greensboro, North Carolina (latitude $36^{\circ} 4^{\prime} 16.63^{\prime \prime}$ longitude $\left.-79^{\circ} 43^{\prime} 33.02^{\prime \prime}\right)$. Greensboro features a humid subtropical climate (Köppen climate classification), which has subtropical summer temperatures and mild winters, and the average annual precipitation is about $107 \mathrm{~cm}$. The mean monthly precipitation, as well as the average, maximum and minimum temperatures by month, are provided in Table 1 for the 2 -year period from 2012 to 2014, during which the experiments took place.

At the NC A\&T SU farm, Berkshire sows are reared outdoors. Generally, the sows are kept in a deep-bedded hoop barn until the last month of pregnancy, during which the sows are moved to a pasture-based unit of 2 acres. The sows are artificially inseminated with semen from Berkshire boars. Farrowing takes place in individual lots of $14 \times 24 \mathrm{~m}^{2}$ with free access to water, shade, and farrowing hut. Piglets are weaned at 4 weeks of age and are reared from the nursery phase to the finishing phase within a separate hoop structure from the sows. The deep bedding used in the hoop structures, generally straw, corn stalks, or hay, are spread approximately 35 to $45 \mathrm{~cm}$ thick, which can provide a comfortable environment for the animals, allowing rooting and other natural behaviors, and help control odors and decrease the risk of manure runoff affecting local water quality. New beddings are added every 5 to 6 weeks. The piglets are fed ad libitum from the time of weaning to the end of the experiments. The nutritional information for the feed used in the different stages of production is provided in Table 2. During gestation, the sows were provided $5 \mathrm{lbs}$. of feed every morning.

\section{Data collection and growth curve modeling}

A total of 274 pigs from 27 sows were used for the study. The BWs were measured at birth and every 4 weeks until 20 weeks of age. Over a 2-year period, 1,258 BW records were generated.

Table 1. Basic monthly meteorological information for North Carolina

\begin{tabular}{lcccc}
\hline \multirow{2}{*}{ Month } & \multicolumn{3}{c}{ Temperature $\left({ }^{\circ} \mathrm{C}\right)$} & $\begin{array}{c}\text { Average } \\
\text { precipitation }(\mathbf{m m})\end{array}$ \\
\cline { 2 - 4 } & Average & Max & Min & 91.69 \\
January & 5.1 & 12.9 & -4.7 & 79.76 \\
February & 6.4 & 14.1 & -0.4 & 96.77 \\
March & 9.7 & 21.7 & 0.4 & 108.46 \\
April & 15.0 & 22.2 & 8.0 & 117.09 \\
May & 19.8 & 26.9 & 12.4 & 135.64 \\
June & 23.3 & 29.9 & 15.8 & 167.64 \\
July & 25.4 & 32.7 & 18.8 & 134.87 \\
August & 23.8 & 29.3 & 18.4 & 107.44 \\
September & 21.2 & 26.9 & 14.9 & 71.37 \\
October & 15.8 & 23.1 & 9.3 & 69.60 \\
November & 8.1 & 15.3 & 1.2 & 116.33 \\
December & 7.8 & 14.3 & 1.4 &
\end{tabular}


Table 2. Nutritional information of the different types of feed used in the experiment

\begin{tabular}{|c|c|c|c|c|c|}
\hline \multirow{3}{*}{ Ingredients } & \multicolumn{5}{|c|}{ Production phase } \\
\hline & \multirow{2}{*}{\multicolumn{2}{|c|}{$\frac{\text { Sow }}{\text { Gestating Lactating }}$}} & \multicolumn{3}{|c|}{ Pig } \\
\hline & & & Starter & Grower & Finisher \\
\hline Crude protein ${ }^{1)}$ & 13.00 & 15.00 & 20.48 & 16.00 & 15.00 \\
\hline Lysine $^{1)}$ & 0.56 & 0.81 & 1.20 & 0.76 & 0.90 \\
\hline (rude fat ${ }^{1)}$ & 3.00 & 6.00 & 5.40 & 3.50 & 3.30 \\
\hline (rude fibers ${ }^{1)}$ & 5.00 & 5.00 & 4.00 & 4.10 & 5.00 \\
\hline Calcium $(\mathrm{Ca})^{1)}$ & 1.43 & 1.45 & 1.22 & 1.15 & 1.08 \\
\hline Phosphorus $(P)^{1)}$ & 0.70 & 0.70 & 0.60 & 0.55 & 0.54 \\
\hline Salt $(\mathrm{NaCl})^{1)}$ & 0.80 & 0.90 & 0.65 & 0.75 & 0.75 \\
\hline Selenium $(\mathrm{Se})^{21}$ & 0.30 & 0.30 & 0.30 & 0.30 & 0.30 \\
\hline $\operatorname{Zinc}(\operatorname{Zn})^{2)}$ & 160 & 150 & 150 & 120 & 110 \\
\hline
\end{tabular}

1) Ingredients measured in percentage.

${ }^{2)}$ Ingredients measured in parts-per-million (ppm).

Reproductive performance records for the sows and the growth performance records for the piglets did not exist for the months of February, March and August. For the months of January and December, the number of BW records did not exceed 100, and therefore were excluded from the analysis. Due to the limited conditions of the outdoor rearing system, however, BW were not always recorded exactly on schedule. Sow aggressiveness, severe weather conditions and etc. caused advancements and postponements of scheduled weighing dates. The BW adjustment was necessary to conform weighing dates between individuals.

Polynomial functions were used to estimate BW on days 0 , $28,56,84,112$, and 140. Existing BW records were plotted and the growth curve was fitted to the points using polynomial functions whose power was determined by the number of existing observations for each individual. Then, the fitted growth curve was used to estimate BW for those whose body weighing schedules were advanced or postponed to conform weight age among individuals.

\section{Statistical analysis}

Least square means of daily BW were estimated with Proc Mixed in SAS 9.4 for fixed effects such as parity, sex and FM. The differences within fixed effects were compared using least significant differences with PDIFF option in SAS 9.4.

\section{RESULTS}

The mean parity ( \pm standard deviation $[\mathrm{SD}]$ ) of the sows was $3.42 \pm 2.14$ and a total of 45 farrowing occurred from year 2012 to 2014. The mean number of total born (TB), number born alive (NBA), number of mummies (NM) and number weaned (NW) were $9.23 \pm 2.52,7.87 \pm 2.53,0.04 \pm 0.21$, and $5.94 \pm 2.74$, respectively. Parity did not have a significant effect on the growth performance of the pigs.

According to the National Oceanic and Atmospheric Administration [9], the hottest months of the year in North Carolina between years 2012 and 2014 were June, July and August, which are generally defined as the summer months in the northern hemisphere (Table 1). It was also during these months that the highest average precipitation measurements were found.

As presented in Table 2, the sows that farrowed in June had the lowest number of TB with an average of $6.25 \pm 2.22$ piglets per sow. However, the lowest average number of piglets weaned at day 28 was found in sows that farrowed in May; the same sows had the highest number recorded for the stillborn piglets with an average of 2.67 piglets per sow. Moreover, the lowest increase in weight from birth to weaning occurred in piglets that were farrowed in May, which also corresponds with the ADG and the last recorded weight measurement on day 140 (Table 3). The pigs that were farrowed in May had an increase of $5.69 \mathrm{~kg}$ in weight from birth to weaning, ADG of $0.29 \mathrm{~kg}$ from birth to 140 day of age (DOA) and average BW of $41.69 \pm 1.45 \mathrm{~kg}$, the lowest recorded closely followed by pigs farrowed in September whose average BW was $43.42 \pm 2.08 \mathrm{~kg}$. Contrastingly, the largest growth was found among pigs farrowed in June, with the largest increase in weight of $7.55 \mathrm{~kg}$ from birth to weaning, the highest ADG of $0.51 \mathrm{~kg}$ from birth to $140 \mathrm{DOA}$ and the highest BW of $74.70 \pm 1.86 \mathrm{~kg}$ recorded on day 140 (Table 3). Pigs farrowed in June also had the least number that died between birth and weaning (Table 2).

As presented in Table 3, birth and wean BW were not affected by the FM. Statistically significant differences began to emerge on day 56 between FM $(\mathrm{p}<0.05)$. On day 56 , pigs farrowed in May and September had significantly lower average BW compared to the average weight of pigs farrowed in June. On day 56 , the average BW of pigs farrowed in May, September and June

Table 3. Arithmetic means and standard deviations of sow reproductive performance by total born

\begin{tabular}{lccccc}
\hline Farrowing month & TB & NBA & NW & LWB & LWW \\
\hline April & $9.29 \pm 2.63$ & $8.57 \pm 2.7$ & $7.29 \pm 2.81$ & $14.40 \pm 5.4$ & $55.87 \pm 17.68$ \\
May & $9.00 \pm 1.79$ & $6.33 \pm 2.07$ & $5.00 \pm 2.1$ & $9.00 \pm 4.3$ & $36.68 \pm 16.47$ \\
June & $6.25 \pm 2.22$ & $5.50 \pm 1.91$ & $5.25 \pm 1.71$ & $14.02 \pm 11.15$ & $56.51 \pm 31.83$ \\
July & $10.50 \pm 3.51$ & $7.88 \pm 2.85$ & $5.25 \pm 2.05$ & $14.74 \pm 6.28$ & $49.16 \pm 22.06$ \\
September & $9.67 \pm 4.16$ & $9.67 \pm 4.16$ & $7.33 \pm 2.08$ & $13.48 \pm 2.59$ & $54.18 \pm 4.15$ \\
October & $10.33 \pm 1.51$ & $8.50 \pm 2.07$ & $7.33 \pm 2.07$ & $5.17 \pm 5.55$ & $26.96 \pm 30.26$ \\
November & $9.33 \pm 1.97$ & $8.33 \pm 2.25$ & $5.17 \pm 3.49$ & $9.83 \pm 5.13$ & $47.62 \pm 18.17$ \\
\hline
\end{tabular}

TB, total born; NBA, number born alive; NW, number weaned; LWB, litter weight at birth; LWW, litter weight at weaning. 
were $10.22 \pm 1.43 \mathrm{~kg}, 12.40 \pm 1.69 \mathrm{~kg}$ and $17.73 \pm 1.71 \mathrm{~kg}$, respectively. The difference between average BW of pigs farrowed in May and September, and June continued until day 140.

On days 84 and 140, pigs farrowed in June had significantly higher average $\mathrm{BW}$ to the rest of the groups. However, on day 112 , no difference was observed between the average BW of pigs farrowed in June and the average of BW of pigs farrowed in October. On day 112, the average BW of pigs farrowed in June and October were $51.25 \pm 1.78 \mathrm{~kg}$ and $47.23 \pm 1.15 \mathrm{~kg}$, respectively. Pigs farrowed in October, whose average BW at birth was the lowest, showed great growth by day 112 , on which the average BW of pigs farrowed in October was not different from the average BW of pigs farrowed in June, whose average BW at birth was the highest. Pigs farrowed in October had the second largest $\mathrm{ADG}$ of $0.48 \mathrm{~kg}$ at the end of the experiments.

Pigs farrowed in May and November had similar average birth weights $(1.49 \pm 1.39 \mathrm{~kg}$ and $1.43 \pm 1.29 \mathrm{~kg}$, respectively). By day 140 , the average BW of pigs farrowed in November was significantly higher from the average BW of pigs farrowed in May. Average BW of pigs farrowed in May and November were $41.69 \pm 1.45 \mathrm{~kg}$ and $56.75 \pm 1.70 \mathrm{~kg}$, respectively. Even though pigs farrowed in May began with a slightly higher birth weight, pigs farrowed in November showed greater growth (Table 3). Initial birth weights should be considered along with the average BW on day 140 in order to compare overall growth of pigs farrowed in different months.

\section{DISCUSSION}

Various functions are considered when modeling the growth curve of animals. Logistic, von Bertalanffy, Gompertz and Richards functions are often applied to BW data from different animals such as cattle [10], poultry [11] and swine [12]. According to Coyne et al [13], suitable parametric growth functions for describing and forward-predicting growth throughout an animal's life are von Bertalanffy, Gompertz, and Richards. In this study, however, polynomial functions were used to estimate BW on days $0,28,56,84,112$, and 140 , considering the short lifespan of the animals used. In general, animals raised in farms are harvested before they reach full maturity, and therefore, growth curve functions that illustrate the full lifespan of the animals are inappropriate. Shull [14] reported simple polynomial or logarithmic equations to provide more accurate estimates between live weight and periodic measures of growth performance in pigs. Kohn et al [15] also reported linear polynomials of third and fourth order of fit as the best fit for BW data in the minipig.

Berkshires are known for their superior meat quality but inferior reproductive performance. The amount of research on the reproductive and growth performance of purebred Berkshires is limited, with majority of the limited research focused on East Asia. Sasaki et al [16] conducted a research in Japan with Berkshire gilts and sow and found similar farrowing performance as the result of the present study. The mean parity $( \pm S D)$ of the sows was 3.0 \pm 2.14 , and the mean numbers of TB, NBA, and NW were $8.9 \pm 2.77,8.4 \pm 2.70$, and $8.0 \pm 1.83$, respectively. The lower mean number of piglets weaned for the present study $(5.94 \pm 2.74)$ could be the result of different rearing systems. The lactating sows were housed indoors with crates for the study conducted in Japan, whereas the present study housed the lactating sows outdoors in pasture-based units with English huts.

In recent years, concern for animal welfare has received increased interest, and the demand for products from systems that consider the natural behaviors of the animals has increased. According to Gade [17], consumers perceive intensive pig farming to generally use synthetic chemicals as medication, growth promoters and feed components. The concern for the use of synthetic chemicals and the demand for organic pork resulted in an increased search for pork production systems that are simpler and less capital-intensive and which conditions are ecological, sustainable and non-intensive [18]. However, the amount of research on factors that can affect animal performance in an outdoor production system is limited, especially when different environments are considered.

In an outdoor production system, pig performance can be significantly affected by climatic conditions [19]. Particularly in North Carolina, where the four seasons are distinctly defined, pig performance can vastly differ with the climatic changes that occur at the turn of the season. One of the key climatic factors that affect pig performance is temperature, and the fact that the zone of thermal comfort (range of temperatures in which an animal feels comfortable) for the lactating sow is notably different from that of the piglet makes it more difficult to rear pigs outdoors. According to Black et al [20], the zones of thermal comfort for the lactating sow and the piglets differed by more than $15^{\circ} \mathrm{C}$ to $18^{\circ} \mathrm{C}$ in indoor confinement system. The difference in the zones of thermal comfort causes discrepancy between the reproductive performance of the sow and the growth performance of the piglet, and therefore, knowing when to impregnate the sows for the best productivity can be lead to higher profit.

High temperature outside the zone of thermal comfort can cause a reduction in feed intake and milk yield for the sow [18]. In indoor confinement, when the sows were housed in higher temperature, feed intake and milk yield were decreased by $25 \%$ and $15 \%$, respectively [21]. Decrease in feed intake and milk yield can lead to decreased reproductive performance for the sow and decreased growth rate for the piglets [22]. In outdoor, alternative production system, the conditions are different. Behavioral restrictions, such as nest-site seeking, nest-building, and maternal interactions with the piglets that exist in an indoor confinement system are not present. Because the sows are not confined to farrowing crates, reproductive performance measured in the amount of milk yield is not accurate. The sows can freely move in and out of the farrowing huts, disturbing the suckling behaviors of the piglets, which can result in a lower average weaning weight. 
Table 4. Least square means and standard errors for piglet growth performance by farrowing month

\begin{tabular}{|c|c|c|c|c|c|c|c|}
\hline \multirow{2}{*}{ Farrowing month } & \multirow{2}{*}{$\begin{array}{l}\text { Average daily gain } \\
(\mathrm{kg} / \mathrm{d})\end{array}$} & \multicolumn{6}{|c|}{ Day of age } \\
\hline & & 0 & 28 & 56 & 84 & 112 & 140 \\
\hline April & 0.38 & $1.64 \pm 1.10^{\mathrm{a}}$ & $8.75 \pm 1.10^{\mathrm{a}}$ & $14.83 \pm 1.29^{\mathrm{ab}}$ & $23.78 \pm 1.43^{\text {cd }}$ & $36.36 \pm 1.17^{b}$ & $54.75 \pm 1.18$ \\
\hline May & 0.29 & $1.49 \pm 1.39^{\mathrm{a}}$ & $7.18 \pm 1.39^{\mathrm{a}}$ & $10.22 \pm 1.43^{c}$ & $17.15 \pm 1.43^{\mathrm{e}}$ & $28.39 \pm 1.43^{c}$ & $41.69 \pm 1.45$ \\
\hline June & 0.51 & $3.35 \pm 1.96^{a}$ & $10.99 \pm 1.71^{\mathrm{a}}$ & $17.73 \pm 1.71^{\mathrm{a}}$ & $35.77 \pm 1.82^{\mathrm{a}}$ & $51.25 \pm 1.78^{\mathrm{a}}$ & $74.70 \pm 1.86$ \\
\hline July & 0.40 & $1.67 \pm 1.22^{\mathrm{a}}$ & $7.88 \pm 1.18^{\mathrm{a}}$ & $14.49 \pm 1.19^{\mathrm{ab}}$ & $24.61 \pm 1.28^{\text {cd }}$ & $38.77 \pm 1.29^{b}$ & $57.89 \pm 1.31$ \\
\hline September & 0.30 & $1.51 \pm 1.63^{\mathrm{a}}$ & $7.63 \pm 1.63^{\mathrm{a}}$ & $12.40 \pm 1.69^{b c}$ & $22.20 \pm 1.90^{d}$ & $29.93 \pm 2.24^{c}$ & $43.42 \pm 2.08$ \\
\hline October & 0.48 & $1.26 \pm 1.15^{\mathrm{a}}$ & $8.06 \pm 1.15^{\mathrm{a}}$ & $15.82 \pm 1.15^{\mathrm{ab}}$ & $29.37 \pm 1.15^{b}$ & $47.23 \pm 1.15^{\mathrm{a}}$ & $68.31 \pm 1.15$ \\
\hline November & 0.40 & $1.43 \pm 1.29^{\mathrm{a}}$ & $8.12 \pm 1.29^{a}$ & $14.38 \pm 1.39^{a b}$ & $27.25 \pm 1.62^{\mathrm{bc}}$ & $38.24 \pm 1.66^{b}$ & $56.75 \pm 1.70$ \\
\hline
\end{tabular}

${ }^{\mathrm{a} e \mathrm{e}}$ Average body weights in the same column with different superscripts differ $(p<0.05)$.

According to Black et al [20], the zone of thermal comfort for the sow is between $12^{\circ} \mathrm{C}$ and $22^{\circ} \mathrm{C}$. The average temperatures for the months of May and September both fall in the zone of thermal comfort for the sows (Table 1). However, sow reproductive performance, measured in the amount of milk yield based on the increase of average piglet BW from birth to weaning, was the worst in May and September (Table 4). Furthermore, the highest number of stillborn and the lowest number of weaned piglets were recorded for May, indicating high stress for the sows. A different stressor, other than the average temperature outside the zone of thermal comfort, existed that caused the lower reproductive performance of the sows in May. According to NOAA, the average precipitation for May 2012 was $158.50 \mathrm{~mm}$, which is larger than the monthly average precipitation for May between 2012 and 2014 by more than $40 \mathrm{~mm}$. The heavy rainfall may be the cause of low reproductive performance in the sows.

The zone of thermal comfort for the piglets is between $30^{\circ} \mathrm{C}$ and $37^{\circ} \mathrm{C}[20]$. The monthly average temperature in North Carolina does not exceed $30^{\circ} \mathrm{C}$. Between 2012 and 2014, the only month when the maximum temperature exceeded the zone of thermal comfort for the piglets was July. In a climate where the monthly average temperatures do not exceed the zone of thermal comfort, the effect of ambient temperature is different from indoor confinement systems where the temperature can be adjusted to meet the needs of the animals accordingly. Overall, the growth performance of the pigs was improved when the ambient temperature was consistently hot or consistently cold. In the present study, pigs farrowed in June had the best growth performance with the highest ADG and BW at the end of the experiment, followed closely by pigs farrowed in October. The average monthly temperature begins to rise above $20^{\circ} \mathrm{C}$ at the turn of the season in June and continues to be relative hotter for the next two months. Contrastingly, the average monthly temperature drops below $20^{\circ} \mathrm{C}$ in October and continues to be cold. The worst growth performance was found in pigs farrowed in May, followed by pigs farrowed in September, which corresponds with the low reproductive performance of the respective sows. A rapid increase in temperature occurred after May, causing a decline in the growth of the pigs. Likewise, the rapid decrease in temperature that occurred in October caused the decline in the growth of the pigs farrowed in September.

\section{IMPLICATIONS}

The zone of thermal comfort found in sows reared in indoor confinement systems did not improve the reproductive performance of the sows reared in an outdoor, alternative production system. The best reproductive performance was found among one of the hottest months of the year. A different stressor, other than the average temperature outside the zone of thermal comfort, may be the cause of lower reproductive performance in sows. Average monthly precipitation should be considered when deciding when to breed the sows for the best reproductive performance. Furthermore, in a climate where the monthly average temperatures do not exceed the zone of thermal comfort for the piglets, the effect of ambient temperature is different from indoor confinement systems. Overall, the growth performance of the pigs was improved when the ambient temperature was consistently hot or consistently cold. Taking into account both the reproductive performance of the sows and the growth performance of the piglets affected by FM, pigs farrowed in June result in the best productivity, and therefore in best profit. Further investigation is needed with larger sample size to confirm the effects of FM on the reproductive performance of the sows and the growth performance of the piglets.

\section{CONFLICT OF INTEREST}

We certify that there is no conflict of interest with any financial organization regarding the material discussed in the manuscript.

\section{ACKNOWLEDGMENTS}

The authors are grateful for supporting research titled in "Outdoor Swine Production Management" by the USDA National Institute of Food and Agriculture, Hatch project number NC.X282-5-14$120-1$.

\section{REFERENCES}


1. Honeyman MS. Extensive bedded indoor and outdoor pig production systems in USA: current trends and effects on animal care and product quality. Livest Prod Sci 2005;94:15-24.

2. Whitley N, Hanson D, Morrow W, See MT, Oh SH. Comparison of pork quality and sensory characteristics for antibiotic free Yorkshire crossbreds raised in hoop houses. Asian-Australas J Anim Sci 2012; 25:1634-40.

3. Kleinbeck SN, McGlone JJ. Intensive indoor versus outdoor swine production systems: Genotype and supplemental iron effects on blood hemoglobin and selected immune measures in young pigs. J Anim Sci 1999;77:2384-90.

4. Sather AP, Jones SDM, Schaefer AL, Colyn J, Robertson WM. Feedlot performance, carcass composition and meat quality of free-range reared pigs. Can J Anim Sci 1997;77:225-32.

5. Muriel E, Ruiz J, Ventanas J, Antequera T. Free-range rearing increases (n-3) polyunsaturated fatty acids of neutral and polar lipids in swine muscles. Food Chem 2002;78:219-25.

6. Suzuki K, Shibata T, Kadowaki H, Abe H, Toyoshima T. Meat quality comparison of Berkshire, Duroc and crossbred pigs sired by Berkshire and Duroc. Meat Sci 2003;64:35-42.

7. Swantek PM, Roush WB, Stender DR, et al. Feed intake and growth rate in purebred berkshire pigs housed in hoop buildings in Iowa; 2013. Animal industry report. AS 659, ASL R2834.

8. Gegner L. Hog production alternatives: ATTRA's Organic Matters Series; 2004.

9. NOAA National Centers for Environmental Information, Climate at a Glance: U.S. Time Series, Precipitation [Internet]; 2016 [cited 2016 Oct 3]. Available from: http://www.ncdc.noaa.gov/cag/

10. Brown JE, Fitzhugh HA Jr., Cartwright TC. A comparison of nonlinear models for describing weight-age relationships in cattle. J Anim Sci 1976;42:810-8.
11. Knizetova H, Hyanek J, Knize B, Roubicek J. Analysis of growth curves of fowl. I. Chickens. Br Poult Sci 1991;32:1027-38.

12. Krieter J, Kalm E. Growth, feed intake and mature size in Large White and Pietrain pigs. J Anim Breed Genet 1989;106:300-11.

13. Coyne JM, Berry DP, Mantysaari EA, Juga J, McHugh N. Comparison of fixed effects and mixed model growth functions in modeling and predicting live weight in pigs. Livest Sci 2015;177:8-14.

14. Shull CM. Modeling growth of pigs reared to heavy weights [Dissertation]. Urbana, IL: University of Illinois at Urbana-Champaign; 2013.

15. Kohn F, Sharifi AR, Simianer H. Modeling the growth of the Goettingen minipig. J Anim Sci 2007;85:84-92.

16. Sasaki Y, Tokunaga T, Uemura R, Sueyoshi M. An assessment of reproductive and lifetime performances of Kagoshima Berkshire gilts and sows. Anim Sci J 2014;85:213-8.

17. Gade PB. Welfare of animal production in intensive and organic systems with special reference to Danish organic pig production. Meat Sci 2002;62:353-8.

18. Miao ZH, Glatz PC, Ru YJ. Review of production, husbandry and sustainability of free-range pig production systems. Asian-Australas J Anim Sci 2004;17:1615-34.

19. Gentry JG, McGlone JJ, Miller MF, Blanton JR Jr. Environmental effects on pig performance, meat quality, and muscle characteristics. J Anim Sci 2004;82:209-17.

20. Black JL, Mullan BP, Lorschy ML, Giles LR. Lactation in the sow during heat stress. Livest Prod Sci 1993;35:153-70.

21. Mullan BP, Brown W, Kerr M. The response of the lactating sows to ambient temperature. Proc Nutr Soc Aust 1992;17:215.

22. Vidal JM, Edwrds SA, MacPherson O, English PR, Taylor AG. Effect of environmental temperature on dietary selection in lactating sows. Anim Prod 1991;52:597. 